\title{
Professional skepticism and auditing
}

Professional skepticism and auditing

A discourse goldmine

Conceived as a behavior, trait, and attitude

Behavioral theorists echo

Due professional care

Trait theorists caution

Beware of recency bias

Attitude theorists?

Endorse critical assessment

Before taming audit risks

Before rotating audit firms

And changing auditors

Or audit Partners

Before adopting a questioning mind

Assessing the auditors' frame of mind

Verify

Conservative-aggressive reporting

Managers engaging under pressure

Diligently

Scrutinized via an eye of presumptive doubt

And a lens of neutrality

Perceiving first their judgment

[...] as (un)trustworthy

Presuming next their accounting [...]

As (dis)honest

All the while

Walking on our profession's grey line

When audits require (un)qualified judgments

When stakeholders request audit statements

Diligently engage in forensic-type audits

Accounting, Auditing \& Accountability Journal Vol. 30 No. 8, 2017 Since reports are legal testaments

Audit with presumptive mindsets 
AAAJ

30,8

1928
And at financial year ends

As accountable stewards

Reviewing audit decisions

When our judgments are final

We pause to ask auditors

"Did you trust, but verify?"

Ifeoluwa Tobi Popoola

Department of Management, University of Mississippi, Oxford, Mississippi, USA, and

Kazeem O. Akinyele

Kenneth G. Dixon School of Accounting, College of Business Administration,

University of Central Florida, Orlando, Florida, USA 